\title{
PREVENTION OF NEEDLE STICK INJURIES
}

\author{
Ms. Indra Devi* | Dr. Bimla Rani** \\ * Research Scholar, Himalayan University, Itanagar, Arunachal Pradesh, India. \\ **Research Supervisor, Himalayan University, Itanagar, Arunachal Pradesh, India. \\ DOI: http://doi.org/10.47211/trr.2020.v06i01.008 \\ Received $10^{\text {th }}$ April 2020, Accepted $5^{\text {th }}$ May 2020, Available online $25^{\text {th }}$ June 2020.
}

\section{ABSTRACT}

Needle sticks are a common occurrence in the health care profession. Of these, many, if not most, go unreported. In response to the risk of exposure, institutions have focused in primary prevention as a means of reducing the incidence of needle sticks and thereby decreasing the number of incidence of needle sticks and thereby decreasing the number of blood borne pathogen transmissions. Needle stick injuries still occur, however, and it is important that individuals in the health care field become well informed about the exposure risks and educated regarding the appropriate response.

The role of the employers of health care workers in preventing needle stick injuries are implementing the use of engineering controls, avoid the use of needles when there are other safer alternatives, implementing use of devices with safety alternatives, implementing the use of devices with safety features, setting priorities and strategies for needle stick injury prevention by examining local and national information about risk factors, ensuring proper training of employees on the safe use and disposal of needles, modifying work practices that have an increased risk of a needle stick injury, promoting safety awareness in the work environment, establishing procedures for and encouraging the reporting of all needle stick and other sharps related injuries, evaluating the effectiveness of prevention efforts and providing feedback on performance. The role of the employees in preventing needle stick injuries are avoiding recapping needles, before beginning any procedure using needles, planning for safe handling and proper disposal, helping the employer select and evaluate devices with safety features, using devices with safety features, reporting needle stick and other sharp related injuries, disposing of used needles in appropriate sharps disposal containers, informing the employer of hazards from needles that are observed at work and participating in blood borne pathogen training and following recommended infection prevention practices, including hepatitis $B$ vaccination.

KEY WORDS: Needle stick, injuries, prevention etc.

\section{ABOUT AUTHORS:}

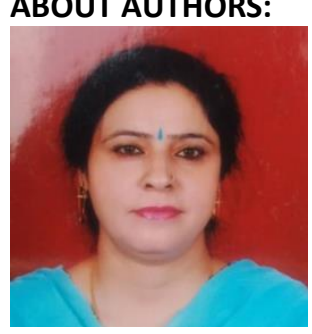

Author Ms. Indra Devi is a Research Scholar at Himalayan University in Itanagar, Arunachal Pradesh, India. She has attended various National and International conferences and workshops.

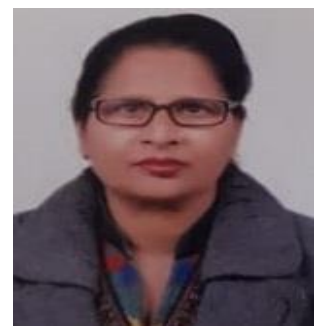

Author Dr. Bimla Rani is a Research Supervisor at Himalayan University in Itanagar, Arunachal Pradesh, India. She has presented papers in various conferences and also has many publications to her name.

\section{INTRODUCTION:}


A penetrating stab wound from a needle (or other sharp object) that may result in exposure to blood or other body fluids is a needle stick injury. The main concern is exposure to the blood or other body fluids of another person who may be carrying infectious disease. The pathogens of primary concern are the human immunodeficiency virus (HIV), hepatitis B virus and hepatitis C virus (HCV).

In case of such a needle stick injury, one should immediately follow these steps:

- Wash needle sticks and cuts with soap and water.

- Flush splashes to the nose, mouth or skin with water.

- In case of splashes to the eyes, irrigate eyes with clean water, saline or sterile irrigating agents.

- If the incident occurs at work, report the incident to the supervisor.

- Immediate medical treatment is a must.

Needle sticks are a common occurrence in the health care profession. It is estimated that $6,00,000$ to $8,00,000$ needle stick injuries occur per year. Of these, many, if not most, go unreported. In response to the risk of exposure, institutions have focused in primary prevention as a means of reducing the incidence of needle sticks and thereby decreasing the number of incidence of needle sticks and thereby decreasing the number of blood borne pathogen transmissions. Needle stick injuries still occur, however, and it is important that individuals in the health care field become well informed about the exposure risks and educate regarding the appropriate response.

The primary pathogens that are transferred are as follows:

1. Human Immunodeficiency Virus (HIV):

The average risk of serconversion after a needle stick injury from a confirmed HIV source is approximately $0.3 \%$ without post-exposure therapy. Certain factors contribute to elevated risk. These are increased depth of the puncture wound, visible blood on the needle, needle used in the vein or artery of the patient and patient with terminal HIV as source of the fluid.

2. Hepatitis B Virus ( HBV):

The risk of acquiring hepatitis secondary to HBV percutaneous exposure varies based on the serological status of the patient. In the worst case scenario, if the patient has active replication of the virus (indicated by HBeAG- positive blood then the risk of developing clinical hepatitis is as high as $31 \%$. When the patient has HBsAG-positive blood but is HBeAG-negative (indicating a less infective state), the risk is significantly lower, about 1 to $6 \%$.

3. Hepatitis C Virus (HCV):

The risk of HCV seroconversion after a needle stick injury from a patient infected with HCV is approximately $1.8 \%$. Unfortunately, there is little evidence to support post exposure treatment as a means to decrease the risk of infection.

Of these three infections, vaccination is available only for HBV. In the 1970s, the risk of acquiring HBV was ten times greater in health care workers than in the general population. This risk has significantly declined, due to an aggressive vaccination campaign geared toward hospital staff. Important facts about the vaccines are as follows:

- A series of 3 shots made from HBsAG is administered.

- Vaccination response can be confirmed by assessing for anti-HBs 2-3 months after completion of the series.

- Protection lasts at least 10 years after vaccination, but may last much longer.

- Currently, no booster is recommended.

A discussion on protocol that should be followed after a needle stick injury is as follows:

Firstly, the person struck with the needle stick injury should not panic.

Protocols are in place to minimize the risk of infection after exposure. Secondly, the exposure should not be ignored. Acting with outlined time frames can lead to a significant decrease in the transmission rate of certain infections. The following measures also should be taken:

- The site should be immediately washed with soap and water.

- The incident should be reported and an exposure report sheet completed.

- The exposure should be assessed (type of fluid, type of needle, amount of blood on the needle etc.)

- The exposure source should be evaluated.

a. HIV, HBV and HCV status of patient;

b. Likelihood of infection based on the community served by the hospital if the patient is not available to be tested.

- Appropriate management of any positive exposure is necessary. 
Virus Specific Post- exposure Management:

1. HIV:

Use of post-exposure prophylaxis can help to reduce the risk of contracting HIV. Maximal benefit can be obtained by initiating treatment within hours of exposure. Guidelines include the following:

- $\quad$ Start post-exposure prophylaxis as soon as possible.

- $\quad$ Re-evaluate the exposed individual within 72 hours, particularly focusing on new information regarding the source and the exposure.

- If the source is determined to be HIV-negative, post-exposure prophylaxis can be discontinued.

- If the source is determined to be HIV-positive, continue treatment for 4 weeks if tolerated.

- $\quad$ All workers exposed to HIV should undergo HIV antibody testing at 6 weeks and 6 months. A few additional considerations regarding HIV exposure management are as follows:

There is the possibility of toxicity with antiretrovirals, so use should be restricted to exposures in which reasonable risk of transmission is present.

2-drug therapy (with 2 nucleoside analogues) is recommended, although 3-drug therapy may be warranted under certain circumstances (i.e. a source with a high viral load or known drug resistance).

One should inform the treating physician about pregnancy status and current medications because these can influence the selection of a treatment regimen.

2. HBV:

The treatment after exposure varies based on the vaccination status of the exposed individual and the HBV status of the patient.

- Regardless of the status of the patient, if an individual suffers a needle stick and is unvaccinated, the vaccination series should be initiated.

- If an individual has been vaccinated and has a document response to the vaccine, then no treatment is required after an exposure.

- If the vaccination status of the exposed individuals is unknown, he or she should be tested for antiHBs before deciding on treatment.

3. HCV:

No treatment has been shown to prevent infection for workers exposed to HCV. Recommendations center on following workers after the injury and monitoring for HCV RNA in the serum. Recommendations include:

- Begin testing for antibodies, HCV RNA levels, and alanine aminotransferase (ALT) levels immediately after the event.

- $\quad$ Repeat testing 2-8 weeks later.

- If infection occurs, the health care worker should be referred to a specialist for management.

\section{What can employers and employees do to prevent a needle stick injury in the workplace?}

\section{- Role of employers:}

- Implement the use of engineering controls to reduce needle stick injuries.

- Avoid the use of needles when there are other safer alternatives.

- Implement use of devices with safety alternatives.

- Implement the use of devices with safety features.

- Set priorities and strategies for needle stick injury prevention by examining local and national information about risk factors.

- Ensure proper training of employees on the safe use and disposal of needles.

- Modify work practices that have an increased risk of a needle stick injury.

- Promote safety awareness in the work environment.

- Establish procedures for and encourage the reporting of all needle stick and other sharps related injuries.

- Evaluate the effectiveness of prevention efforts and provide feedback on performance.

\section{- Role of employees:}

\section{- Avoid recapping needles}

- Before beginning any procedure using needles, plan for safe handling and proper disposal.

○ Help the employer select and evaluate devices with safety features. 
- Use devices with safety features.

- Report needle stick and other sharp related injuries.

- Dispose of used needles in appropriate sharps disposal containers.

- Inform the employer of hazards from needles that are observed at work.

- Participate in blood borne pathogen training and follow recommended infection prevention practices, including hepatitis $B$ vaccination.

\section{REFERENCES:}

1. Centers for Disease Control and Prevention. Updated US public health service guidelines for the management of occupational exposures to HBV, HCV, and HIV and recommendations for post exposure prophylaxis.

2. Crawford JM. The liver and the biliary tract. In: Cotran RS, Kumar V, Collins T, eds. Robbins Pathological Basis of Disease. 6th ed. New York, NY: WB Saunders; 1999:845-901.

3. Henry K, Campbell S. Needle stick/sharps injuries and HIV exposure among health care workers: national estimates based on a survey of US hospitals. Minn Med. 1995; 78:41-44.

4. https://journalofethics.ama-assn.org/article/management-needlestick-injuries-health-care-setting/2005-10

5. https://www.medsafe.com/blog/osha-compliance/5-steps-to-take-following-a-needlestick-and-how-toprevent-an-injury-in-the-workplace

6. National Institute for Occupational Safety and Health. NIOSH Alert: Preventing needle stick injuries in health care setting. NIOSH Publication No. 2000-108. Washington, DC: National Institute for Occupational Safety and Health; 1999. Available at: http://www.cdc.gov/niosh/2000-108.html. Accessed September 2, 2005.

7. National Institutes of Health. NIH Consensus Statement on Management of Hepatitis C: 2002. NIH Consens State Sci Statements. 2002 June 10-12; 19:1-46.

8. Teo EK, Lok ASF. Hepatitis B virus vaccination. Available at: http://uptodateonline.com. Accessed August 11, 2005.

9. Yuen MF, Lim WL, Chan AO, et al. 18-year follow-up study of a prospective randomized trial of hepatitis $B$ vaccinations without booster doses in children. Clin Gastroenterol Hepatol. 2004; 2(10):941-945. 